\title{
BMJ Open Psychometric properties of the Breast Cancer Awareness Measurement among Chinese women: a cross-sectional study
}

\author{
Na Liu, ${ }^{1}$ Ping Li, ${ }^{2}$ Jie Wang, ${ }^{1}$ Dan-dan Chen, ${ }^{1}$ Wei-jia Sun, ${ }^{1}$ Ping-ping Guo, ${ }^{1}$ \\ Xue-hui Zhang, ${ }^{1}$ Wei Zhang (i) ${ }^{1}$
}

To cite: Liu N, Li P, Wang J, et al. Psychometric properties of the Breast Cancer Awareness Measurement among Chinese women: a crosssectional study. BMJ Open 2020;10:e035911. doi:10.1136/ bmjopen-2019-035911

- Prepublication history and additional material for this paper are available online. To view these files, please visit the journal online (http://dx.doi. org/10.1136/bmjopen-2019035911).

Received 21 November 2019 Revised 13 February 2020 Accepted 14 February 2020

Check for updates

(c) Author(s) (or their employer(s)) 2020. Re-use permitted under CC BY-NC. No commercial re-use. See rights and permissions. Published by BMJ.

${ }^{1}$ Nursing School of Jilin University, Jilin University, Changchun, Jilin, China

${ }^{2}$ Developmental Pediatrics, Jilin University Second Hospital, Changchun, Jilin, China

Correspondence to

Dr Wei Zhang;

hlzhangw99@163.com

\section{ABSTRACT}

Objectives To perform the cross-cultural adaption of the Breast Cancer Awareness Measurement (BCAM) and to test its psychometric properties among Chinese women. Design This is a cross-sectional study.

Settings This study was conducted in communities, schools and institutions in Changchun, Jilin Province, China.

Participants A total of 328 women voluntarily participated in and completed the Chinese version of the BCAM (CBCAM), resulting in an effective response rate of $91.1 \%$.

\section{Primary and secondary outcome}

measures Psychometric properties, including item analysis (the extreme group comparison and item-total correlations), content validity (item-level content validity index (I-CVI) and scale-level content validity index (S-CVI)), construct validity (exploratory factor analysis (EFA) and confirmatory factor analysis (CFA)) and internal consistency (Cronbach's $\alpha$ and test-retest reliability), were measured. Results The C-BCAM has excellent internal consistency (Cronbach's $\alpha=0.90$ ), with alpha coefficients of $0.88,0.84$ and 0.94 for its three domains. The test-retest reliability coefficient was 0.72 . The I-CVI ranged from 0.86 to 1.00 , and the S-CVI was 0.92 . CFA showed that the threefactor model explained $51.56 \%$ of the total variance, with a good model fit (likelihood ratio $\chi^{2} / \mathrm{df}=1.86$, incremental fit index $=0.94$, comparative fit index $=0.94$, goodness-of-fit index $=0.84$, adjusted goodness-of-fit index $=0.80$, standardised root mean square error of approximation $=0.06$ and root mean square residual $=0.05$ ). Conclusions The C-BCAM has satisfactory validity and reliability and is a culturally appropriate and reliable tool for evaluating breast cancer awareness among Chinese women. This reliable instrument can help researchers and health professionals evaluate women's knowledge about the symptoms and risk factors of breast cancer and identify their barriers to seeking medical help. It also helps healthcare providers identify women with poor breast cancer awareness and encourage them to perform screening practice.

\section{INTRODUCTION}

Breast cancer is the most commonly diagnosed cancer and the leading cause of cancer-related death among women. The Global Cancer database provided a report on the global burden of cancer, reporting that in

\section{Strengths and limitations of this study}

This study is the first to introduce and validate the Chinese version of the Breast Cancer Awareness Measurement (C-BCAM) to assess breast cancer awareness.

- A comprehensive analysis was conducted to test the psychometric properties of the C-BCAM.

- The limitations of the sample may make the results less representative of all Chinese women.

- Breast cancer awareness assessment based on participants' self-reports may lead to partial bias.

- The applicability of the C-BCAM needs to be verified in larger and more regional samples.

all surveyed areas, the number of new breast cancer cases was almost 2088849 (11.6\%) and the number of breast cancer deaths was $626679(6.6 \%) .{ }^{1}$ In the USA, breast cancer accounts for $30 \%$ (266 120) of all newly diagnosed cancers and 14\% (40 920) of all cancer deaths in women. ${ }^{2}$ Similarly, there were 279000 new breast cancer cases in China. ${ }^{3}$ Additionally, statistics in 2014 showed that the incidence $\left(34.4 / 10^{5}\right)$ and mortality $\left(8.5 / 10^{5}\right)$ of breast cancer in northeast China were the highest. ${ }^{3}$ Notably, a diagnosis of breast cancer aggravates women's depressive symptoms and significantly decreases their physical functioning, mental health and quality of life. ${ }^{4}$ In addition, body changes caused by treatment can affect women's lives, including their sexual functioning, body image and intimate relationships, which can dramatically alter their life satisfaction. ${ }^{5}$ Despite significant advances in related research, breast cancer remains a challenging health concern and a top priority for biomedical research..$^{6}$ Thus, there is an urgent need to develop measures to improve the prognosis of breast cancer.

It has been widely recognised that breast cancer screening can increasingly reduce mortality over time and improve the prognosis of patients. ${ }^{7}$ Previous studies have 
demonstrated that early detection and screening can substantially increase the detection rate of small breast tumours to $68 \%$ and effectively decrease breast cancer mortality by approximately $20 \% .^{8}$ Breast cancer screening aims to find breast cancer while it is still curable to reduce unnecessary breast cancer-specific mortality. ${ }^{10}$ The Chinese Anti-Cancer Association, the Committee of the Breast Cancer Society and the National Comprehensive Cancer Network have recommended that women should perform regular breast cancer screening. ${ }^{11} 12$ Meanwhile, guideline ${ }^{12}$ recommends that the methods of breast cancer screening should include breast selfexamination, clinical breast examination, mammography, breast ultrasonography and MRI. Although this guideline suggests that breast self-examination and clinical breast examination may not reduce the mortality rate of breast cancer and increase the detection rate, these methods are still positively significant in improving women's awareness of breast cancer screening early diagnosis of breast cancer $^{12}{ }^{13}$; thus, they are still recommended as desirable screening methods. Therefore, the effectiveness of screening has been largely recognised and affirmed. Notably, increased breast cancer screening has led to an increase in overdiagnosis of breast cancer (an estimated $11 \%-19 \%$ of all breast cancers) in particular invasive and ductal carcinoma in situ or early stage cancers. ${ }^{14}$ Therefore, healthcare sector and health professionals should provide women invited for screening with information in a transparent and objective manner so that they can make informed decisions. ${ }^{15}$

However, a lack of breast cancer screening awareness, perceived risks, less concern about screening and perceived screening barriers may affect individuals' screening practices. ${ }^{16-18}$ Women's health awareness of cancer and cancer screening is the key factor affecting their screening behaviour. ${ }^{19}$ Breast cancer awareness refers to whether women have a good knowledge of breast cancer and the ability and confidence to detect changes in their breasts and to report them to healthcare providers in a timely manner. ${ }^{20}$ It is associated with a lack of breast cancer knowledge, fear of the results, a lack of support from the surrounding environment and the screening cost. ${ }^{21}{ }^{22}$ Therefore, a comprehensive assessment of women's breast cancer awareness, including an accurate analysis of their knowledge of breast cancer, screening barriers and other contents, can help health professionals identify individuals with poor breast cancer awareness and conduct targeted interventions. It also facilitates joint screening decisions between individuals and healthcare providers, which in turn helps to improve women's health and quality of life and to reduce the adverse effects of breast cancer.

The Breast Cancer Awareness Measurement (BCAM), validated by Linsell $e t a l^{23}$ is a reliable instrument for assessing breast cancer awareness in UK women. It is easier to understand than adult books and performs well among young and old adult women. ${ }^{23}$ It focuses on specific early breast cancer signs and perceived barriers to breast cancer screening, differentiating it from other available instruments. ${ }^{24}{ }^{25}$ Several psychometric studies have evaluated the properties of the BCAM in a diverse population, and all of them have reported satisfactory validity and reliability. ${ }^{25-27}$ This suggests that the BCAM is an effective tool for evaluating women's breast cancer awareness. However, there are no studies in which the BCAM is culturally adapted for China to form an instrument for assessing Chinese women's awareness of breast cancer, and China lacks standardised tools. Therefore, the purpose of this study is to conduct a cross-cultural adaption and psychometric validation of the BCAM in Chinese women.

\section{METHODS}

\section{Participants}

Screening guidelines ${ }^{12}$ suggested that regular breast cancer screening should be given to both women with general risk and those at high risk of breast cancer. And the sample population of the other BCAM versions ${ }^{25-27}$ in other countries were the general community women. Therefore, our study also adopted a convenient sampling method and recruited general community women to participate in the survey.

For reliability and validity testing and factor analysis, the sample size should be 5-10 times the number of items in the scale and should be $>300$ participants. ${ }^{28}{ }^{29}$ At the same time, an invalid response rate of $10 \%-20 \%$ should also be considered; thus, a total of 360 questionnaires were issued. Therefore, cross-sectional descriptive research was conducted on 360 asymptomatic women from communities, schools, institutions and other places in Changchun, Jilin Province, China, from January to April 2019. To ensure sociodemographic heterogeneity, participants with different ages, occupations, educational levels and other characteristics were purposefully selected. The inclusion criteria were as follows: (a) $\geq 18$ years of age $e^{25} 27$ (while most breast cancer screening should begin at age 40 , the assessment of breast cancer awareness should not be limited to women older than 40 years); (b) no communication barriers (deafness or blindness); (c) no diagnosis of breast cancer and (d) no diagnosis of severe cardiovascular disease or mental disturbance. All participants were informed of the aim of this study and had the right to refuse to participate or withdraw from the study without consequence.

\section{The Breast Cancer Awareness Measurement}

Based on the Cancer Awareness Measure (CAM), ${ }^{30}$ Cancer Research UK, King's College London and University College London jointly developed the Breast Module-CAM (BCAM) to evaluate women's breast cancer awareness. Linsell $e t a l^{23}$ verified the reliability and validity of the BCAM. The instrument includes seven domains: (1) knowledge of symptoms; (2) confidence, skills and behaviour in relation to detecting a breast change; (3) anticipated delay in contacting the doctor; (4) barriers to 
seeking medical help; (5) knowledge of age-related and lifetime risk; (6) knowledge of the NHS Breast Screening Programme and (7) knowledge of risk factors. Based on the advice of experts, we focused on four domains (domains 1, 2, 4, 7) that applied to the Chinese population in this study, while completely unsuitable domains, such as the NHS Breast Screening Programme domain, were not considered. For the cultural adaption and application of the BCAM, the author of the original scale, Dr Linsell, was contacted, and authorisation was obtained.

\section{Instrument development}

The C-BCAM was developed and evaluated in two phases: (I) the BCAM was translated into the C-BCAM to verify its content validity and (II) the reliability and validity of the C-BCAM were tested.

\section{Phase I: translation, expert consultations and cognitive interviews} With the permission of the original authors, in this study, the BCAM was translated into Chinese. ${ }^{23}$ Brislin translation theory ${ }^{31}$ was used to forward-translate and backtranslate the BCAM. First, two translators independently translated the English version of the BCAM into Chinese, and then, three researchers examined and adjusted it due to the differences between the original and translated versions and reached a consensus on the forwardtranslated version. Then, two other translators separately back-translated the forward-translated version into English and cross-examined and finalised it as the backtranslated English version. Afterwards, six researchers discussed and revised the translated version based on the BCAM for conceptual, idiomatic, semantic and content equivalence until they all agreed on the translation.

Subsequently, a panel of 14 experts, consisting of 6 educational experts and 8 clinical experts, was invited to complete two rounds of expert consultation. The experts were asked to evaluate the content validity of each item in the translated version and to provide feedback. Meanwhile, 15 women were recruited to participate in cognitive interviews to understand their awareness of breast cancer and to assess their attitudes towards breast cancer screening. The results of the expert consultations and cognitive interviews were incorporated into the revision and validation of the translated version, and the preliminary version of the C-BCAM was finalised. This version included four domains with 30 items.

\section{Phase II: psychometric property evaluation}

A pilot survey of the preliminary version of the C-BCAM was conducted with a sample of 20 women in Changchun, Jilin Province, China, who were invited to assess whether the preliminary version of the C-BCAM was easy to understand. Based on the evaluation results, the wording was modified. Then, the psychometric properties of the preliminary version of the C-BCAM were evaluated in terms of item analysis, content validity, construct validity, internal consistency and test-retest reliability.

\section{Data collection}

The researchers adopted two methods for data collection: online data collection through SO JUMP, ${ }^{32}$ a professional platform and on-site data collection in the form of paper questionnaires. The online data collection process included the following: first, the questionnaire was input into a computer to develop an electronic version of C-BCAM. Second, the e-questionnaire was sent online to individuals via the WeChat application.

\section{Data analysis}

Data were analysed using SPSS V.25.0. The categorical variables were counted using frequency and percentages, the continuous variables had a skewed distribution and the median (M) and IQR were used; $\mathrm{p}<0.05$ was considered to be statistically significant.

Item analysis was conducted based on the following analyses: (a) extreme group comparison (items should discriminate between the scoring groups of the upper $27 \%$ and lower 27\% $)^{33}$ and (b) item-total correlations (the correlation between the score of each item and the total score of the scale). Items with a critical ratio (CR) $>3.0$ or an item-total correlation between 0.30 and 0.80 were retained. ${ }^{34}{ }^{35}$ Content validity was tested using the content validity index, including the item-level content validity index (I-CVI) and the scale-level content validity index (S-CVI). An I-CVI of 0.78 or higher and an S-CVI of 0.80 were considered acceptable. ${ }^{36}$ If the correlation between the factors is $>0.30$, then principal factor analysis with the oblique rotation method is used for exploratory factor analysis (EFA); otherwise, the orthogonal rotation method is used. ${ }^{37}$ Additionally, confirmatory factor analysis (CFA) was conducted using AMOS V.23.0. The Kaiser-Meyer-Olkin test and Bartlett's test of sphericity should be performed before CFA to determine whether factor analysis is suitable. When the Kaiser-Meyer-Olkin value $\geq 0.6$ and Bartlett's test of sphericity is significant at $\mathrm{p}<0.05$, the scale is suitable for conducting factor analysis. ${ }^{38}$ In this study, the sample population was divided into two parts based on the coding order of questionnaire collection to conduct EFA $(n=118)$ and CFA $(n=210)$. In addition, internal reliability and stability were tested through Cronbach's $\alpha$ and test-retest reliability, respectively. Cronbach's $\alpha$, with an $\alpha$ value between 0.80 and 0.90 , suggests an excellent internal coefficient. ${ }^{39}$ Testretest reliability (2-week interval) ${ }^{35}$ in a convenience sample of 20 was examined using the Pearson's correlation coefficient.

\section{Patient and public involvement}

No patient was involved. In the process of expert consultation and scale translation, clinical experts, educational experts and translators were regarded as public participants involved in this study. No participants were involved in this study during the development, design or execution process of this instrument. The results of this study will be made available to members of the public interested in this subject. 


\section{RESULTS}

\section{Characteristics of the participants}

A total of 360 women were recruited for this study, and based on the inclusion criteria, 328 completed the questionnaire, resulting in a $91.1 \%$ response rate. The age of the participants varied from 19 to 67 years, with a median of 35 . In general, the majority of the women had a spouse (60.4\%), had a specialty/bachelor's degree (48.2\%), did not have a family history of breast cancer $(97.3 \%)$, did not receive breast self-examination training $(71.3 \%)$, did not have abnormal breast symptoms $(68.3 \%)$, did not have a breast disease diagnosis $(71.0 \%)$ and had not been screened in the past 2 years $(53.0 \%)$. The sociodemographic characteristics of the participants are presented in table 1.

\section{Psychometric analysis}

Item analysis

Based on the results of the expert consultations and cognitive interviews, 13 items from the original scale were deleted, 2 items were merged and 11 new items were added. The preliminary version of the C-BCAM included 30 items and 4 domains.

Based on the results of the extreme group comparison, the CR value of all items exceeded 3.0; thus, 30 items were temporarily retained. Then, the Spearman's correlation method was adopted to calculate the correlation between items and the total score. The coefficients of 7 items were $<0.3$; however, the correlation coefficients of items 9,10 and 12 were very close to 0.3 and temporarily retained. Therefore, the preliminary version of the C-BCAM contained three domains consisting of 26 items (table 2).

\section{Validity}

\section{Content validity}

After the first round of expert consultations, the second round of expert consultations was conducted to assess the content validity of the preliminary version of the C-BCAM. The I-CVI was calculated based on the number of people giving an expert rating of 3 or 4 for each item, and the S-CVI was calculated from the average of the I-CVI of all items. The results showed that the I-CVI ranged from 0.86 to 1.00 and that the S-CVI was 0.92 , indicating that the C-BCAM has excellent content validity.

\section{Construct validity}

The Kaiser-Meyer-Olkin measure of the C-BCAM was 0.78 , and Bartlett's test of sphericity was also satisfactory $(\mathrm{p}=0.00)$, which means that the 26-item C-BCAM was suitable for conducting factor analysis. Use of the oblique rotation method extracted six factors with eigenvalues $>1.0(7.23,3.89,2.29,1.47,1.13$ and 1.05$),{ }^{40}$ and the total variance explained by these factors was $65.58 \%$. According to the screen plot (figure 1) and the factor structure of the original scale, ${ }^{40}$ we decided that the number of common factors extracted from the scale was three $(7.23,3.89,2.29)$, and these three factors explained $51.56 \%$ of the total variance (figure 2 ).
Table 1 Characteristics of the included participants $(n=328)$

\begin{tabular}{|c|c|}
\hline Characteristics & Median (range)/N (\%) \\
\hline Age, years & 35 (19 67) \\
\hline \multicolumn{2}{|l|}{ Employment status } \\
\hline Employed & $162(49.4)$ \\
\hline Unemployed & $103(31.4)$ \\
\hline Students & $63(19.2)$ \\
\hline \multicolumn{2}{|l|}{ Marital status } \\
\hline Without spouse & $130(39.6)$ \\
\hline With spouse & $198(60.4)$ \\
\hline \multicolumn{2}{|l|}{ Education level } \\
\hline Junior school or below & $73(22.3)$ \\
\hline $\begin{array}{l}\text { High school/specialised secondary } \\
\text { school }\end{array}$ & $35(10.7)$ \\
\hline Specialty/Bachelor & $158(48.2)$ \\
\hline Postgraduate or above & $62(18.9)$ \\
\hline \multicolumn{2}{|l|}{ Average income ( $¥$, monthly) } \\
\hline$<2000$ & $71(21.6)$ \\
\hline $2000 \sim 4000$ & $121(36.9)$ \\
\hline $4001 \sim 6000$ & $59(18.0)$ \\
\hline$>6000$ & $77(23.5)$ \\
\hline \multicolumn{2}{|l|}{ Family history of breast cancer } \\
\hline Yes & $9(2.7)$ \\
\hline No & $319(97.3)$ \\
\hline \multicolumn{2}{|l|}{ Family history of cancer } \\
\hline Yes & $32(9.8)$ \\
\hline No & $296(90.2)$ \\
\hline \multicolumn{2}{|l|}{$\begin{array}{l}\text { History of breast self-examination } \\
\text { training }\end{array}$} \\
\hline Yes & $94(28.7)$ \\
\hline No & $234(71.3)$ \\
\hline \multicolumn{2}{|l|}{ Abnormal breast symptoms } \\
\hline Yes & $104(31.7)$ \\
\hline No & $224(68.3)$ \\
\hline \multicolumn{2}{|l|}{ History of breast disease diagnosis } \\
\hline Yes & $95(29.0)$ \\
\hline No & $233(71.0)$ \\
\hline \multicolumn{2}{|l|}{ Breast cancer screening history } \\
\hline $\begin{array}{l}\text { Have been screened in the past } \\
2 \text { years }\end{array}$ & $174(53.0)$ \\
\hline Never had a screening & $154(47.0)$ \\
\hline
\end{tabular}

The CFA results suggested that the goodness of fit of the adjusted three-factor model was good. Specifically, likelihood ratio $\chi^{2} / \mathrm{df}=1.86$, incremental fit index $=0.94$, comparative fit index $=0.94$, goodness-of-fit index $=0.84$, adjusted goodness-of-fit index $=0.80$, standardised root mean square error of approximation $=0.06$ and root mean square residual $=0.05$.

\section{Reliability}

The Cronbach's $\alpha$ coefficient of the C-BCAM was 0.90, and the coefficients of the knowledge of symptoms, barriers to seeking medical help and knowledge of risk factors domains 


\begin{tabular}{|c|c|c|c|c|}
\hline Item & CR & $\begin{array}{l}\text { Item-total } \\
\text { correlations }\end{array}$ & $\begin{array}{l}\text { Cronbach's } \alpha \text { if } \\
\text { item deleted }\end{array}$ & Note \\
\hline B1 & $7.246^{*}$ & $0.403^{*}$ & 0.895 & Retained \\
\hline B2 & $8.519^{\star}$ & $0.443^{*}$ & 0.894 & Retained \\
\hline B3 & $8.492^{*}$ & $0.459^{*}$ & 0.893 & Retained \\
\hline B4 & $7.095^{\star}$ & $0.403^{\star}$ & 0.894 & Retained \\
\hline B5 & $9.012^{*}$ & $0.432^{*}$ & 0.894 & Retained \\
\hline B6 & $4.536^{\star}$ & $0.257^{*}$ & 0.898 & Deleted \\
\hline B7 & $5.134^{*}$ & $0.275^{*}$ & 0.897 & Deleted \\
\hline B8 & $3.590^{\star}$ & $0.190^{\star}$ & 0.897 & Deleted \\
\hline B9 & $5.059^{*}$ & $0.297^{*}$ & 0.894 & Retained \\
\hline B10 & $5.192^{\star}$ & $0.280^{*}$ & 0.894 & Retained \\
\hline B11 & $3.993^{*}$ & $0.234^{*}$ & 0.896 & Deleted \\
\hline B12 & $4.589^{\star}$ & $0.284^{*}$ & 0.895 & Retained \\
\hline B13 & $9.220^{*}$ & $0.481^{*}$ & 0.893 & Retained \\
\hline B14 & $8.351^{\star}$ & $0.422^{*}$ & 0.893 & Retained \\
\hline B15 & $5.728^{*}$ & $0.314^{*}$ & 0.895 & Retained \\
\hline B16 & $12.133^{*}$ & $0.650^{\star}$ & 0.887 & Retained \\
\hline B17 & $7.303^{*}$ & $0.430^{*}$ & 0.892 & Retained \\
\hline B18 & $13.497^{\star}$ & $0.688^{*}$ & 0.887 & Retained \\
\hline B19 & $14.290^{*}$ & $0.681^{*}$ & 0.887 & Retained \\
\hline B20 & $9.794^{\star}$ & $0.535^{\star}$ & 0.890 & Retained \\
\hline B21 & $10.111^{*}$ & $0.582^{*}$ & 0.889 & Retained \\
\hline B22 & $10.971^{*}$ & $0.612^{*}$ & 0.888 & Retained \\
\hline B23 & $9.836^{*}$ & $0.560^{*}$ & 0.889 & Retained \\
\hline B24 & $7.505^{\star}$ & $0.470^{\star}$ & 0.891 & Retained \\
\hline B25 & $9.504^{*}$ & $0.557^{*}$ & 0.890 & Retained \\
\hline B26 & $7.846^{\star}$ & $0.488^{*}$ & 0.890 & Retained \\
\hline B27 & $12.780^{*}$ & $0.646^{*}$ & 0.887 & Retained \\
\hline B28 & $10.837^{\star}$ & $0.590^{*}$ & 0.889 & Retained \\
\hline B29 & $9.194^{*}$ & $0.541^{*}$ & 0.890 & Retained \\
\hline B30 & $11.547^{*}$ & $0.621^{*}$ & 0.887 & Retained \\
\hline
\end{tabular}

${ }^{*} \mathrm{P}<0.01$.

were $0.88,0.84$ and 0.94 , respectively. The coefficient of test-retest reliability was 0.72 , indicating that the C-BCAM has satisfactory stability (table 3 ) (see online supplementary appendix).

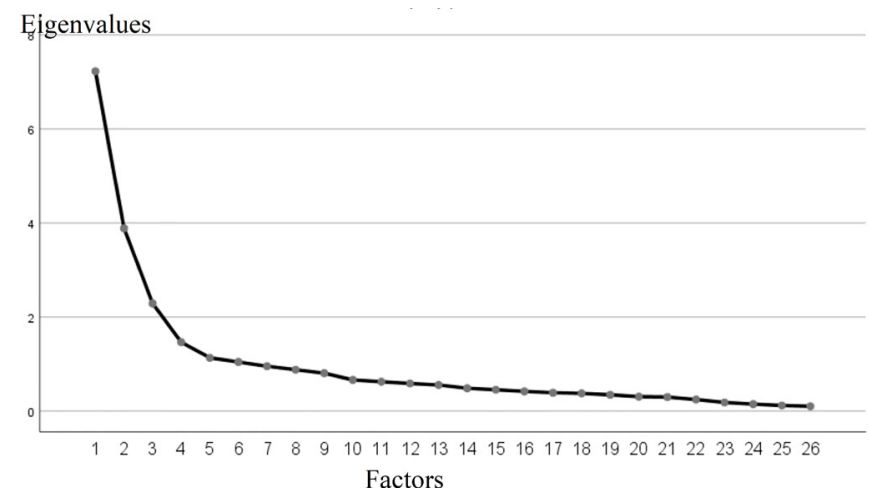

Figure 1 The screen plot.

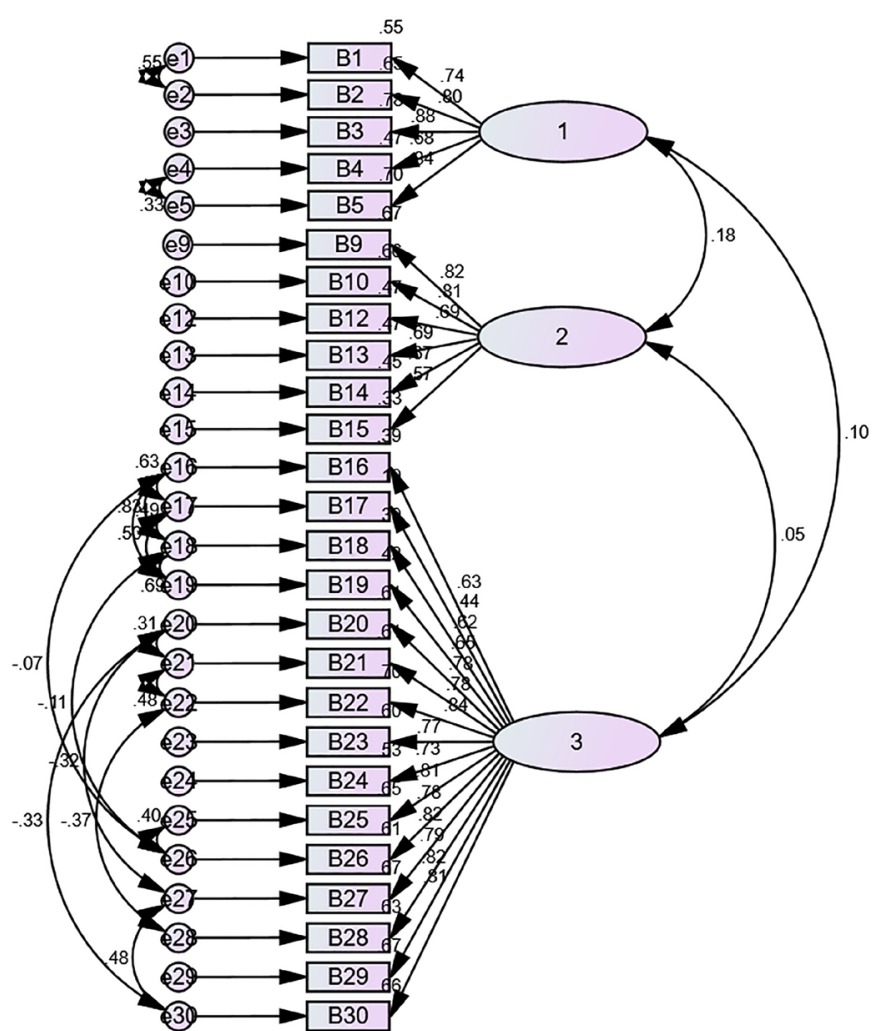

Figure 2 Standardised three-factor structural equation model diagram.

\section{DISCUSSION}

This study aimed to translate and culturally adapt the BCAM into Chinese and to examine the psychometric properties of C-BCAM. In general, the C-BCAM had satisfactory internal consistency (Cronbach's $\alpha=0.90$ ), test-retest reliability (coefficient $=0.72$ ), content validity and construct validity. The three-factor model explained $51.56 \%$ of the total variance. Therefore, the results indicated that the C-BCAM has good reliability and validity and can be a reliable measurement tool. This instrument provides an effective and comprehensive method for clinical healthcare professionals to identify the status of Chinese women's breast cancer awareness and to predict their screening practices to further develop scientific and reasonable breast cancer screening measures for the medical sector to provide means of evaluation.

Compared with the BCAM, ${ }^{23}$ the C-BCAM showed satisfactory psychometric properties. Specifically, the Flesch reading ease score of the BCAM was 87.9 , indicating that

\begin{tabular}{lcl}
\hline \multicolumn{2}{l}{ Table 3} & Results of internal consistency \\
\hline Domains & Items & Cronbach' $\boldsymbol{\alpha}$ \\
\hline Knowledge of symptoms & 5 & 0.88 \\
Barriers to seeking medical help & 6 & 0.84 \\
Knowledge of risk factors & 15 & 0.94 \\
C-BCAM scale & 26 & 0.90
\end{tabular}

C-BCAM, Chinese version of the Breast Cancer Awareness Measurement. 
BCAM was easier to read than adult reading material. In addition, $91 \%(231 / 253)$ of the participants reported that it was easier to read, and $96 \%(244 / 253)$ reported that the questions on the scale were not upsetting. Most of the participants recruited in this study had a higher level of education, but the remaining $33 \%$ of participants with a lower level of education also reported that the C-BCAM was easy to understand, and none of them reported that it violated their privacy. Except for the lump in the breast item (0.28), the other items in the BCAM showed moderateto-good kappa statistic values (0.42-0.70). Compared with the BCAM (kappa statistic $=0.28-0.70$ ), the C-BCAM had a better test-retest result (coefficient value $=0.72$ ). Meanwhile, it should be noted that most experts considered that nipple rash and redness of the skin are not specific symptoms of breast cancer; thus, the related items in the C-BCAM were removed. Therefore, the C-BCAM formed by culturally adapting the BCAM is a reliable and effective tool for evaluating the level of breast cancer awareness of Chinese women.

There are three available versions of the BCAM. BCAMKenyan ${ }^{25}$ focuses on two domains (knowledge of symptoms and barriers to breast cancer screening). Similar to BCAM-Kenyan, the C-BCAM avoided double-barrelled questions with the conjunction 'or' in the statements and divided these questions in the BCAM into multiple single questions. To avoid misunderstanding, the BCAM-Kenyan changed all statement items in the barriers to seeking medical help domain into questions. Similarly, the C-BCAM includes a question title and 15 statements to avoid ambiguity. Compared with the BCAM-Kenyan, the C-BCAM reported higher internal consistency ( 0.80 vs 0.90$)$. The BCAM-Arab includes four domains, including early signs, early detection practices, awareness of age-related risks and awareness of general risk factors. ${ }^{26}$ Compared with the internal consistency of the BCAM-Arab (0.89 and 0.86), the C-BCAM has better internal consistency (Cronbach's $\alpha=0.90$ ). The Persian version of the $\mathrm{BCAM}^{27}$ has three domains, including knowledge of breast cancer symptoms, knowledge of age-related risk and frequency of breast checking, and it has excellent test-retest reliability (coefficient $=0.84$ ) and internal consistency (Cronbach's $\alpha=0.88$ ). Compared with the BCAM-Persian, the C-BCAM had better internal consistency.

This study identified the validity and reliability of the C-BCAM and suggested that it can be used as an assessment tool for assessing breast cancer awareness in Chinese women. Although we have made several revisions on the basis of the original scale, all the modifications are based on the suggestions of experts and the characteristics of China's medical systems to make the instrument more suitable for Chinese women. Healthcare providers and policymakers can use this tool to evaluate women's awareness of breast cancer to identify individuals with poor awareness levels and to further develop targeted interventions and public measures to improve the level of public screening awareness. Notably, the specific cut-off value of the C-BCAM is critical to the assessment of women's awareness level. Future studies should take this as the focus to formulate a reasonable and scientific standard value to identify women with insufficient screening awareness.

Similar to the other versions ${ }^{25-27}$ of the BCAM, we studied adult women over the age of 18 , both young and old. Although breast cancer is more common in women over 40 , it is also a social problem in younger women. ${ }^{41}$ Age is an independent risk factor for poor prognosis in patients with breast cancer. ${ }^{42}$ Although the incidence of breast cancer in China is lower than that in America, the proportion of younger women with breast cancer is higher. In China, the age-specific incidence of breast cancer increases with age, and the incidence increases rapidly with age after the age of 30 , reaching a peak in the age group of those over $55 .^{43} \mathrm{~A}$ multicentre retrospective study reported that approximately $7.06 \%$ (395) of patients with breast cancer are between the ages of 21 and 34, and young women with higher educational backgrounds are more likely to develop breast cancer. ${ }^{44}$ A growing number of young women are being diagnosed with advanced disease, which is a direct result of a lack of screening and prevention in this age group. Compared with elderly women, young women have a higher recurrence rate and a poorer prognosis. ${ }^{414}$ Therefore, assessing breast cancer awareness and screening practices across all groups of women, including young women, is the key to developing targeted screening strategies and improving prognosis.

This study has several limitations. First, the sample was from Jilin Province in northeast China, representing the level of breast cancer awareness among women in areas with the highest incidence and mortality of breast cancer. However, more than half of the participants lived in cities and had a specialty/bachelor's degree or above; thus, the results were not representative of all Chinese women. Second, a mixture of on-site paper questionnaires and online electronic questionnaires was used for recruitment, and the results collected online may contribute to the bias caused by a lack of sample heterogeneity. Third, this study verified the reliability and validity of the scale in China but failed to further evaluate the level of individual breast cancer awareness, such as the determination of the cut-off value. Additionally, an in-depth analysis of its influencing factors, such as the histories of screening and histories of breast disease, was lacking. Thus, the C-BCAM needs to be further verified in more diverse populations.

\section{CONCLUSIONS}

The results showed that the C-BCAM includes 3 domains, a total of 26 items and has satisfactory internal consistency (Cronbach's $\alpha=0.90$ ). It is an effective and concise instrument for evaluating the breast cancer awareness of Chinese women, assessing their knowledge of breast cancer symptoms, perceived screening barriers and risk factors. This instrument can be used for future related studies to evaluate individual-level factors that may affect breast cancer screening participation and to provide potentially modifiable targets for interventions that ultimately improve individuals' screening decisions and participation. 
Acknowledgements The authors would like to thank the experts who guided the study and the students who worked hard for it. The authors would also like to thank the original author of the scale.

Contributors NL conducted the analysis plan, conducted the data collection and analysis, interpreted the findings and drafted the manuscript. PL confirmed and modified the back-translated version of the BCAM. JW, D-dC and W-jS reviewed the manuscript, revised it critically for important intellectual content. P-pG and X-hZ conducted data collection and analysis. WZ was responsible for the study design, supervised the study, led the data collection, contacted experts to translate and revise the manuscript and approved the final draft.

Funding This work was supported by the China Postdoctoral Science Foundation (2019T120242).

Competing interests None declared.

Patient consent for publication Not required.

Ethics approval This study was approved by the Institutional Review Board of the College of Nursing, Jilin University (access number: 2019010702).

Provenance and peer review Not commissioned; externally peer reviewed.

Data availability statement Data are available on reasonable request.

Open access This is an open access article distributed in accordance with the Creative Commons Attribution Non Commercial (CC BY-NC 4.0) license, which permits others to distribute, remix, adapt, build upon this work non-commercially, and license their derivative works on different terms, provided the original work is properly cited, appropriate credit is given, any changes made indicated, and the use is non-commercial. See: http://creativecommons.org/licenses/by-nc/4.0/.

ORCID iD

Wei Zhang http://orcid.org/0000-0002-1061-882X

\section{REFERENCES}

1 Bray F, Ferlay J, Soerjomataram I, et al. Global cancer statistics 2018: GLOBOCAN estimates of incidence and mortality worldwide for 36 cancers in 185 countries. CA Cancer J Clin 2018:68:394-424.

2 Siegel RL, Miller KD, Jemal A. Cancer statistics, 2018. CA Cancer J Clin 2018;68:7-30.

3 Chen W, Sun K, Zheng R, et al. Cancer incidence and mortality in China, 2014. Chin J Cancer Res 2018;30:1-12.

4 Jones SMW, LaCroix AZ, Li W, et al. Depression and quality of life before and after breast cancer diagnosis in older women from the women's health Initiative. J Cancer Surviv 2015;9:620-9.

5 Male DA, Fergus KD, Cullen K. Sexual identity after breast cancer: sexuality, body image, and relationship repercussions. Curr Opin Support Palliat Care 2016;10:66-74.

6 Anastasiadi Z, Lianos GD, Ignatiadou E, et al. Breast cancer in young women: an overview. Updates Surg 2017;69:313-7.

7 van Schoor G, Moss SM, Otten JDM, et al. Increasingly strong reduction in breast cancer mortality due to screening. $\mathrm{Br} J$ Cancer 2011;104:910-4

8 Myers ER, Moorman P, Gierisch JM, et al. Benefits and harms of breast cancer screening: a systematic review. JAMA 2015;314:1615-34.

9 Welch HG, Prorok PC, O'Malley AJ, et al. Breast-Cancer tumor size, overdiagnosis, and mammography screening effectiveness. $N$ Engl Med 2016;375:1438-47.

10 Niell BL, Freer PE, Weinfurtner RJ, et al. Screening for breast cancer. Radiol Clin North Am 2017;55:1145-62.

11 Goetz MP, Gradishar WJ, Anderson BO, et al. NCCN guidelines insights: breast cancer, version 3.2018. J Natl Compr Canc Netw 2019;17:118-26.

12 The Chinese Anti-Cancer Association CotBCS. Clinical practice guidelines in breast cancer (version 2017). Chin Oncol 2017;27:695-759.

13 Zhang J, Chen W, Liu L. Updates and interpretations of the National comprehensive cancer network guidelines for breast cancer screening and diagnosis (version 1, 2017). Chin Gen Pract 2017;20:2939-43.

14 Marmot MG, Altman DG, Cameron DA, et al. The benefits and harms of breast cancer screening: an independent review. $\mathrm{Br} J$ Cancer 2013;108:2205-40.

15 Independent UK Panel on Breast Cancer Screening. The benefits and harms of breast cancer screening: an independent review. Lancet 2012;380:1778-86.
16 Uchida K, Ohashi H, Kinoshita S, et al. Breast cancer screening and the changing population pyramid of Japan. Breast Cancer 2015;22:172-6.

17 Jiang T, Wei D, Sha R, et al. Psychological factors and demands for breast and cervical cancer screening. Patient Educ Couns 2018;101:1270-5.

18 Ogunsiji OO, Kwok C, Fan LC. Breast cancer screening practices of African migrant women in Australia: a descriptive cross-sectional study. BMC Womens Health 2017;17:32

19 Carter-Harris L, Slaven JE, Monohan P, et al. Development and psychometric evaluation of the lung cancer screening health belief scales. Cancer Nurs 2017:40:237-44.

20 O'Mahony M, Comber H, Fitzgerald T, et al. Interventions for raising breast cancer awareness in women. Cochrane Database Syst Rev 2017;2:CD011396.

21 Abu-Helalah MA, Alshraideh HA, Al-Serhan A-AA, et al. Knowledge, barriers and attitudes towards breast cancer mammography screening in Jordan. Asian Pac J Cancer Prev 2015;16:3981-90.

22 Xie T, Sun W, Chen D, et al. Self-efficacy and its influencing factors of breast cancer screening for female college students in China. J Obstet Gynaecol Res 2019;45:1026-34.

23 Linsell L, Forbes LJL, Burgess C, et al. Validation of a measurement tool to assess awareness of breast cancer. Eur J Cancer 2010:46:1374-81.

24 Liu N, Wang J, Chen D-D, et al. Tools for the assessment of breast cancer screening beliefs in women: a literature review. J Comp Eff Res 2019;8:645-55.

25 Wachira J, Busakhala A, Chite F, et al. Refining a questionnaire to assess breast cancer knowledge and barriers to screening in Kenya: psychometric assessment of the BCAM. BMC Health Serv Res 2017;17:110.

26 Al-Khasawneh EM, Leocadio M, Seshan V, et al. Transcultural adaptation of the breast cancer awareness measure. Int Nurs Rev 2016;63:445-54.

27 Heidari Z, Feizi A. Transcultural adaptation and validation of the Persian version of the breast cancer awareness measure (BCAM) questionnaire. Cancer Med 2018;7:5237-51.

28 Gorsuch RL. Factor analysis. 2nd edn. NJ: Lawrence Erlbaum, 1983.

29 Comrey AL. A first course in factor analysis. New York: Academic Press, 1973.

30 Stubbings S, Robb K, Waller J, et al. Development of a measurement tool to assess public awareness of cancer. $\mathrm{Br} J$ Cancer 2009;101(Suppl 2):S13-17.

31 Brislin RW. Back-Translation for cross-cultural research. J Cross Cult Psychol 1970;1:185-216.

32 JUMP S. Available: https://www.wjx.cn/?source

33 Odukoya JA, Adekeye O, Igbinoba AO, et al. Item analysis of university-wide multiple choice objective examinations: the experience of a Nigerian private university. Qual Quant 2018;52:983-97.

34 Stewart AL. Measuring functioning and well-being: the medical outcomes study approach. CA: Duke University Press, 1992.

35 Thoyre SM, Pados BF, Park J, et al. The pediatric eating assessment tool: factor structure and psychometric properties. J Pediatr Gastroenterol Nutr 2018;66:299-305.

36 Lynn MR. Determination and quantification of content validity. Nurs Res 1986;35:382-5.

$37 \mathrm{Hu}$ Y, Leeuwen RV, Li F. Psychometric properties of the Chinese version of the spiritual care competency scale in nursing practice: a methodological study. BMJ Open 2019;9:e030497.

38 Frank C, Asp M, Fridlund B, et al. Questionnaire for patient participation in emergency departments: development and psychometric testing. J Adv Nurs 2011;67:643-51.

39 DeVellis RF. Scale development: theory and applications. 3rd edn. Thousand Oaks, California: Sage, 2012.

40 Rattray J, Jones MC. Essential elements of questionnaire design and development. J Clin Nurs 2007;16:234-43.

41 Radecka B, Litwiniuk M. Breast cancer in young women. Ginekol Pol 2016;87:659-63.

42 Kroman N, Jensen MB, Wohlfahrt J, et al. Factors influencing the effect of age on prognosis in breast cancer: population based study. BMJ 2000;320:474-8.

43 Chen W, Zheng R. Incidence, mortality and survival analysis of breast cancer in China. Chin J Clin Oncol 2015;42:668-74.

44 Bai-lin Z, Qian Z P, et al. The risk factors of breast cancer in young women in China: a multi-center ten-years retrospective study. Chin Cancer 2015;24:1042-7. 